\title{
Differential punishment of other behavior: Effects of pause-dependent shock on variable-interval performance
}

\author{
O. J. SIZEMORE and F. R. MAXWELL \\ Southwest Missouri State University, Springfield, Missouri
}

\begin{abstract}
Three albino rats were exposed to a differential-punishment-of-other-behavior shock schedule superimposed on a variable-interval schedule of food presentation. With this arrangement, failure to barpress for a specified interval since the previous response resulted in delivery of shock. This procedure reliably decreased the number of specified pauses and was accompanied by increases in barpress rates and shifts in the distribution of responses. Subsequent exposure to noncontingent shock produced similar, but quantitatively smaller, changes for two of the three subjects. Training with barpress-dependent shock and reexposure to noncontingent shock further diminished these effects. This study demonstrates that pauses are conditionable units of behavior insofar as they are sensitive to a punishment contingency. In terms of the targeted unit of behavior, the current findings are similar to those obtained with barpress-dependent or interresponse-time-dependent shock schedules and suggest a continuum of response specification.
\end{abstract}

One aspect of the molecular analysis of behavior has focused on the sensitivity of interresponse time (IRT) to contingencies. Anger (1956), Shimp (1966, 1969), and Staddon (1968), for example, have shown that selective reinforcement of short or long IRTs produces a distribution of responses and rates of response appropriate to the respective contingencies. More recently, this analysis was extended to punishment. Galbicka and Branch (1981) used an IRT $>t$ punishment schedule superimposed on a variableinterval (VI) schedule of food delivery. This procedure decreased the number of long IRTs and was accompanied by an increase in the number of short IRTs and overall rate of response. Successive shortening of the $t$ parameter further shifted the distribution of responses and increased rate of response. Previous studies had demonstrated the effect of IRT $<$ t punishment schedules (e.g., Ferster, 1958), but these studies are difficult to interpret, because several other procedures can produce the same effect. That is, IRT $<t$ punishment will lower rate of response and produce increased numbers of long IRTs. Noncontingent shock can produce this effect (Rachlin \& Herrnstein, 1969), as will responsedependent shock delivered irrespective of IRT length (Galbicka \& Branch, 1981).

The effects of IRT $>t$ shock obtained by Galbicka and Branch (1981) seem to be inconsistent with the wealth of data regarding the effect of shock on barpressing. Since all punishers in their study were contiguous with barpresses, a decline in response rate

The authors' mailing address is: Psychology Department, Southwest Missouri State University, Springfield, Missouri 65802. would be expected. Consistency is obtained by redefining the unit of response that is affected. The organism's repertoire is viewed as a distribution of response-pause-response units (IRTs), which are sensitive to contingencies. The term "interresponse time" technically refers to the pause component of this unit, but is generally used to refer to the entire sequence. While numerous studies have investigated the properties of IRTs and their use in the experimental analysis of behavior, few authors have focused on the role of the pause component. One reason for this paucity of data is the technical difficulty of measuring all possible alternatives to barpressing. While some authors have selected a few of these interim behaviors for study (Bond, Blackman, \& Scruton, 1973; Flory \& Lickfett, 1974; Laties, Weiss, Clark, \& Reynolds, 1965), this only narrows the response class and the role of nonspecific responses remains unclear. Compromise positions have involved using time as an index of those behaviors or assuming (but not necessarily measuring) an inverse relation between responses and pauses.

Rachlin and Herrnstein (1969) attempted unsuccessfully to affect pauses with punishment. Their study, however, was designed to assess not the sensitivity of pauses to punishment, but rather the symmetry of two classes of behavior, responses and pauses. Pause-dependent and response-dependent events were scheduled in separate components of a multiple schedule with pauses defined as 5-sec intervals without any responses. A variable-interval schedule was then used to program the availability of reinforcers and punishers. This arrangement is problematic, however, because pauses of varying 
lengths could be contacted by these stimuli. That is, if pauses are defined as 5-sec intervals without responses and a variable interval schedule is employed, it is possible to predict only the minimum duration of the contacted pause and not its actual duration. The conclusion that pauses are insensitive to punishment does not seem warranted, and the issue therefore invites further investigation.

The present study was designed to investigate the effects of pause-dependent shock. In an attempt to consistently contact pauses of the same length, only those pauses following a barpress were punished (i.e., successive pauses of the same duration were not punished). This schedule could be termed a differential-punishment-of-other-behavior (DPO) shock schedule or a differential-not-respondinggreater-than-t $(d \bar{R}>t)$ shock schedule, where $t$ is a time parameter (Lattal \& Poling, 1981; Zeiler, 1977). Although the former term enhances the risk of confusing a theoretical account of the effects with the schedule of shock delivery, it will be used for the remainder of the paper. The initials DPO will be substituted for the sake of linguistic simplicity. The current arrangement is similar to the technique used by Galbicka and Branch (1981) in that only a portion of the targeted response units were contacted by the punisher; it is different from the technique used by Rachlin and Herrnstein (1969) in that they specified only a minimum pause length and not a maximum pause. A response-dependent shock condition was included in the current study to determine whether the level of shock was indeed punitive, and a response-independent shock condition was included to assess the role of the contingent arrangement versus the effect of the shock, per se.

\section{METHOD}

\section{Subjects}

Three Holtzman albino rats were maintained at $80 \%( \pm 10 \mathrm{~g})$ of their free-feeding weights. Rats B1 and B3 were female, and B1 had been previously exposed to shock during a pilot study.

\begin{abstract}
Apparatus
The experimental space was a Coulbourn Instrument (E10-10) modular test cage. A lever was mounted $7 \mathrm{~cm}$ above the floor in the center of the work panel. A force of approximately $.18 \mathrm{~N}$ was required to operate the lever. A 6-W light, located in the center of the work panel $27 \mathrm{~cm}$ above the floor, illuminated the cage continuously during experimental sessions. The experimental cage was located in a ventilated, sound-attenuated room.

Reinforcers consisted of 45-mg Noyes pellets delivered by a Gerbrands pellet dispenser. Punishment consisted of footshock delivered via stainless steel rods, spaced $1.7 \mathrm{~cm}$ center to center, which constituted the floor of the cage. A Coulbourn Instruments (E13-35) solid state shocker delivered scrambled shocks. Solid state programming and recording equipment were in a separate room.
\end{abstract}

\section{Procedure}

Following preliminary barpress training, behavior was stabilized with a VI 40 -sec schedule. This schedule remained in effect during all phases of the experiment. In addition to re- cording the number of responses and reinforcers, the distribution of responses was divided into five $1-\sec$ intervals or bins. A sixth bin recorded IRTs greater than $10 \mathrm{sec}$ in duration. Nonresponses (pauses) were also recorded. During baseline and control conditions, failure to respond for a specified interval $(8,10$, or $12 \mathrm{sec})$ incremented a counter and, during experimental conditions, also delivered a shock. Shocks were $.35 \mathrm{sec}$ in duration and $.3 \mathrm{~mA}$ in intensity in all conditions in which shock was delivered.

Table 1 shows the sequence of conditions and the number of sessions each was in effect for each rat. Following stability on the VI 40-sec schedule, all rats were exposed to differential punishment of other behavior (DPO). A DPO 12-sec schedule was selected for initial exposure based upon previous pilot data. This schedule is analogous to differential reinforcement of other behavior (DRO) except that it is punishers that are delivered rather than reinforcers. The DPO requirement was always initiated by a barpress, and each completion resulted in the delivery of shock. Further pausing had no scheduled consequences. All rats were exposed to this phase of the experiment at least twice. In some instances, the value of the DPO was decreased to permit more contact with the contingency.

All rats were exposed to noncontingent shock (NCS) in an attempt to separate the effect of the shock contingency from the effect of shock, per se. All rats were exposed to this condition for 12 days. Shocks were equal in number to those delivered during the first and last 6 days of the immediately preceding DPO schedule. A microprocessor-based random-number generator was used to determine the temporal distribution of shocks within each session.

In those cases in which noncontingent shock produced response rate increases, rats were then exposed to barpress-dependent shock (punishment). This condition was included to evaluate the effectiveness of the shock as a punisher and as an attempt to change any stimulus value the shock might have acquired during DPO training. Rat G6 was not exposed to this condition, but instead returned to the DPO condition. During the punishment condition for Rats B1 and B3, contingencies were arranged to provide numbers and distributions of shocks equivalent to those delivered during noncontingent shock. Decreased responding, however, could alter the actual number and distribution of shocks.

Following exposure to response-independent shock, Rats B1 and B3 were reexposed to noncontingent shock. This procedure was included to evaluate the effect of prior responsedependent shock on subsequent noncontingent-shock presentations. Numbers and distributions of shock were identical to those in the previous NCS condition.

Changes from baseline to DPO and from DPO to baseline were made only when behavior was stable. Stability was defined as the occurrence of a 6-day period in which the mean of the first 3 days and the mean of the last 3 days did not differ by more than $\pm 2.5 \%$ of the 6-day mean. Noncontingent shock conditions and punishment conditions were in effect for 12 days regardless of the rat's behavior. Sessions were conducted 5 days per week, and each session lasted $40 \mathrm{~min}$.

\section{RESULTS}

Table 1 shows the average number of pauses per session for each condition. Exposure to DPO decreased the absolute number of specified pauses per session for all rats across all values of DPO investigated. The suppression of pauses was always more complete for Rats B1 and B3 than for Rat G6. Exposure to noncontingent shock (NCS) decreased the number of pauses, although not to the extent observed during DPO. The low number of pauses observed during the barpress-dependent shock condition are a 
Table 1

Sequence of Experimental Conditions, Number of Sessions Each Was in Effect, Pauses per 40-Min Session, Responses per Minute, and Reinforcement Frequency Expressed as Reinforcers per Minute

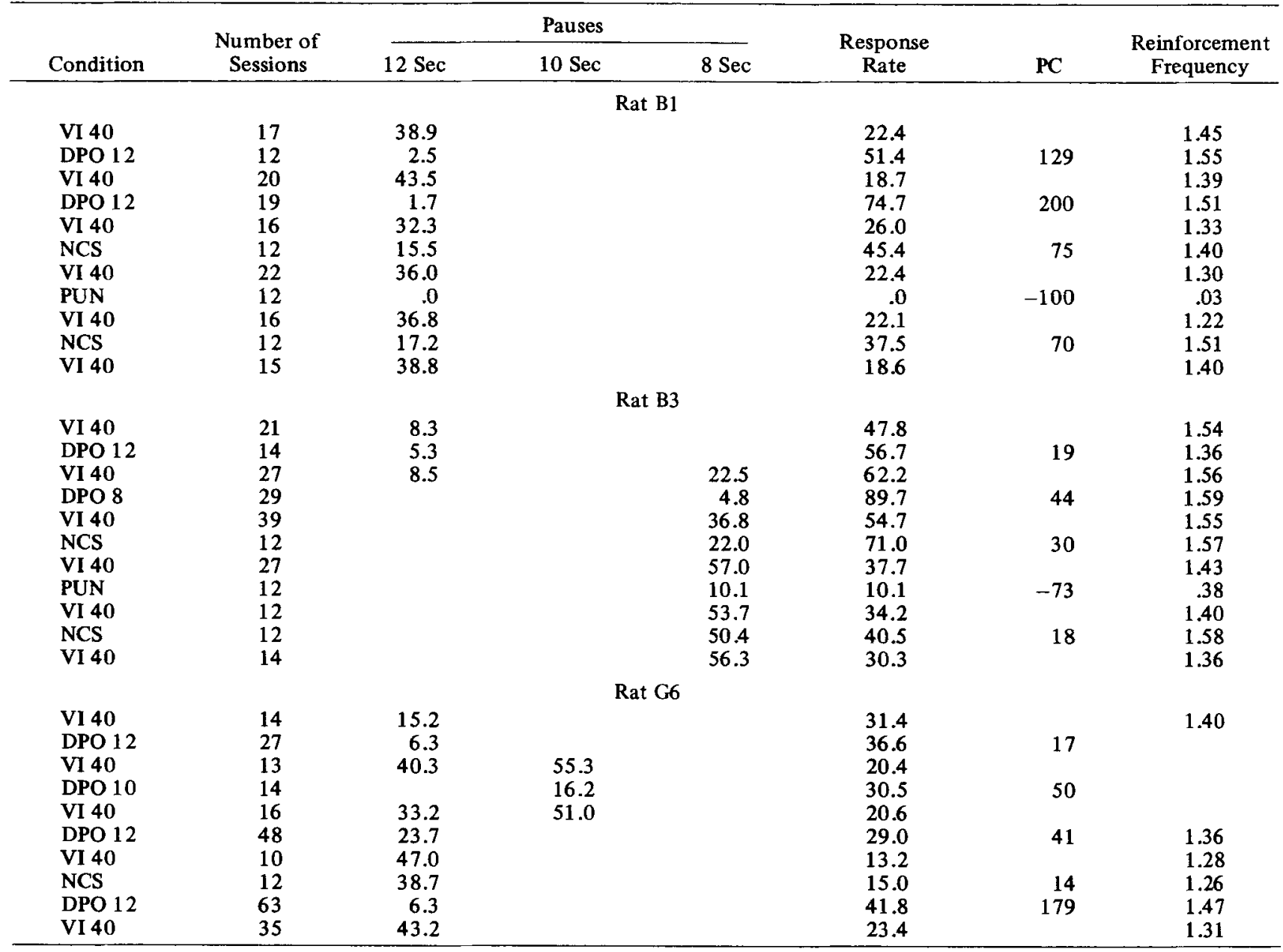

Note $-P C=$ percent change in response rate relative to the previous baseline for all shock conditions. For conditions in which the value of DPO was changed across exposures, pause data are presented for both values. All data are the average of the last 6 days of that condition.

reflection of extremely low barpress rates and the manner in which pauses were defined. ${ }^{1}$

Changes in response rate as a function of condition are shown in Figure 1. Solid lines separate experimental conditions, and the dashed lines separate the first and last 6 days of each condition.

The data are also summarized in Table 1 as mean rates for the last 6 days of each condition. Change relative to the previous baseline, in percent, is shown in parentheses.

In general, response rates were inversely related to pause rates. Exposure to DPO was accompanied by increases in response rate for each case. For Rat B3, the initial baseline was not recovered, but subsequent exposure to DPO 8 sec showed a marked increase relative to both previous baselines.

Figure 1 also shows the effects of noncontingent shock (NCS) on response rate. For Rats B1 and B3, this condition increased rate, although not to the extent observed during DPO; for G6, the response rate obtained during NCS did not change systematically. Since the number of shocks delivered during the condition was matched by session with those delivered during the most recent DPO condition, the observed differences in behavior among subjects could be related to the number of shocks delivered to Rat G6 during NCS (mean $=23.7$ vs. means of 1.7 and 4.8 for B1 and B3, respectively). Alternatively, one could suggest that low-density shock, per se, produced the increase in response rate during NCS and, perhaps, during DPO as well. To assess this possibility and determine if the shock level was punitive, Subjects B1 and B3 were exposed to barpressdependent shock and then reexposed to NCS. The elimination of barpresses by shock demonstrates the aversiveness of the selected shock level. Reex- 

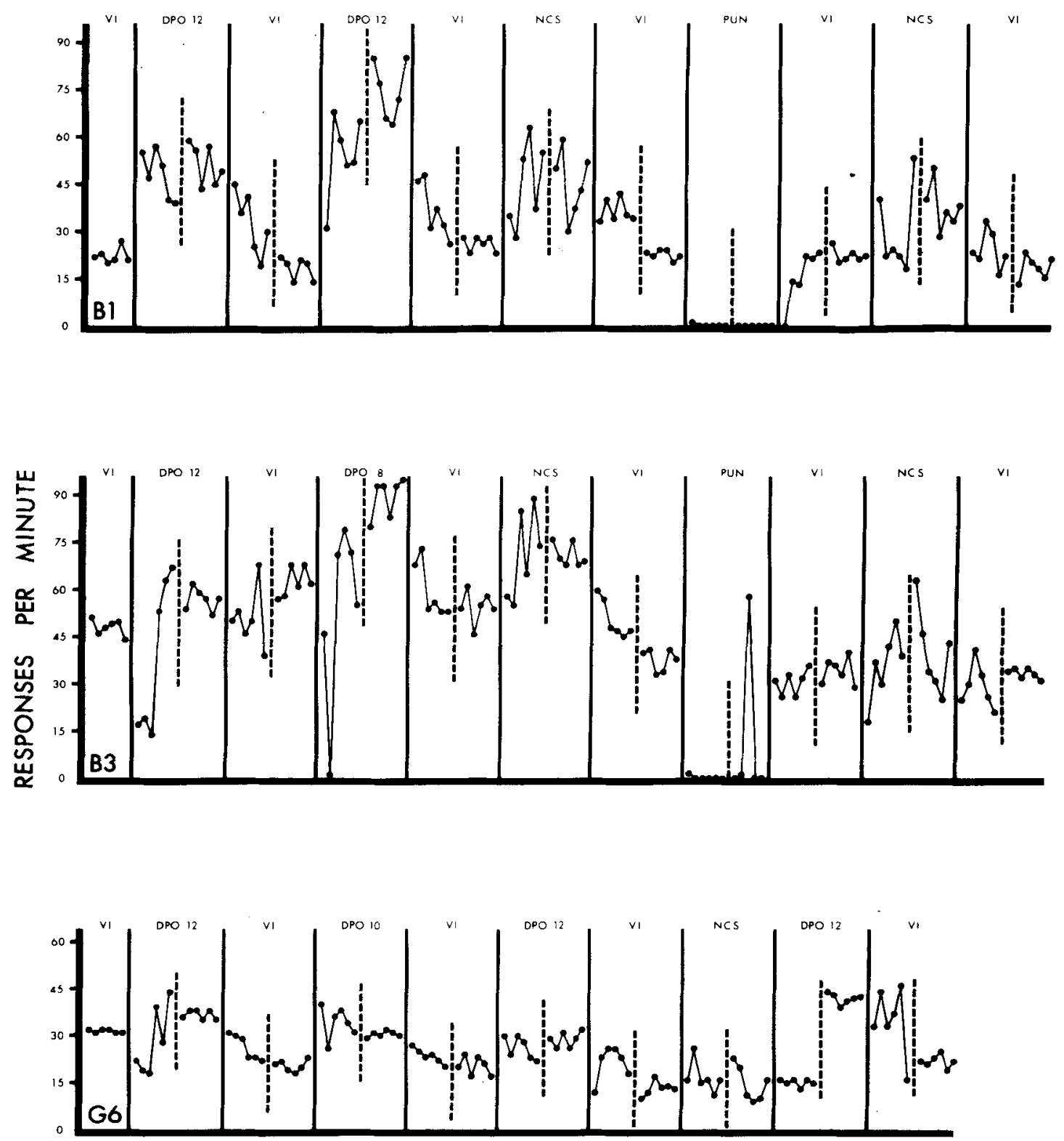

\section{SESSIONS}

Figure 1. Responses per minute for the first and last six sessions of each condition. Different conditions are separated by solid lines, and the first and last six sessions are separated by a dashed line. The number to the right of each DPO notation indicates the pause length that was punished. NCS and PUN refer to noncontingent shock and barpress-dependent shock, respectively.

posure of Rats B1 and B3 to NCS following recovery from the barpress-dependent shock condition, revealed no systematic effect of NCS on rate.

Of particular interest are the changes in response rate for Rats B3 and G6 upon initial exposure to DPO 12 sec. For these subjects, response rates were initially lower relative to baseline and then recovered within a few sessions to levels equal to or greater than baseline. These lower rates, however, were not evident throughout an entire session, but instead reflected a combination of two local rates. Figure 2 shows the cumulative records for B3 prior to and during the first 5 days of DPO training. Note that during DPO the local rate for the last quarter of each session was roughly equal to or greater than baseline rates. As training proceeded, this local rate became higher and occupied more of the session. This trend was also evident for G6. It 

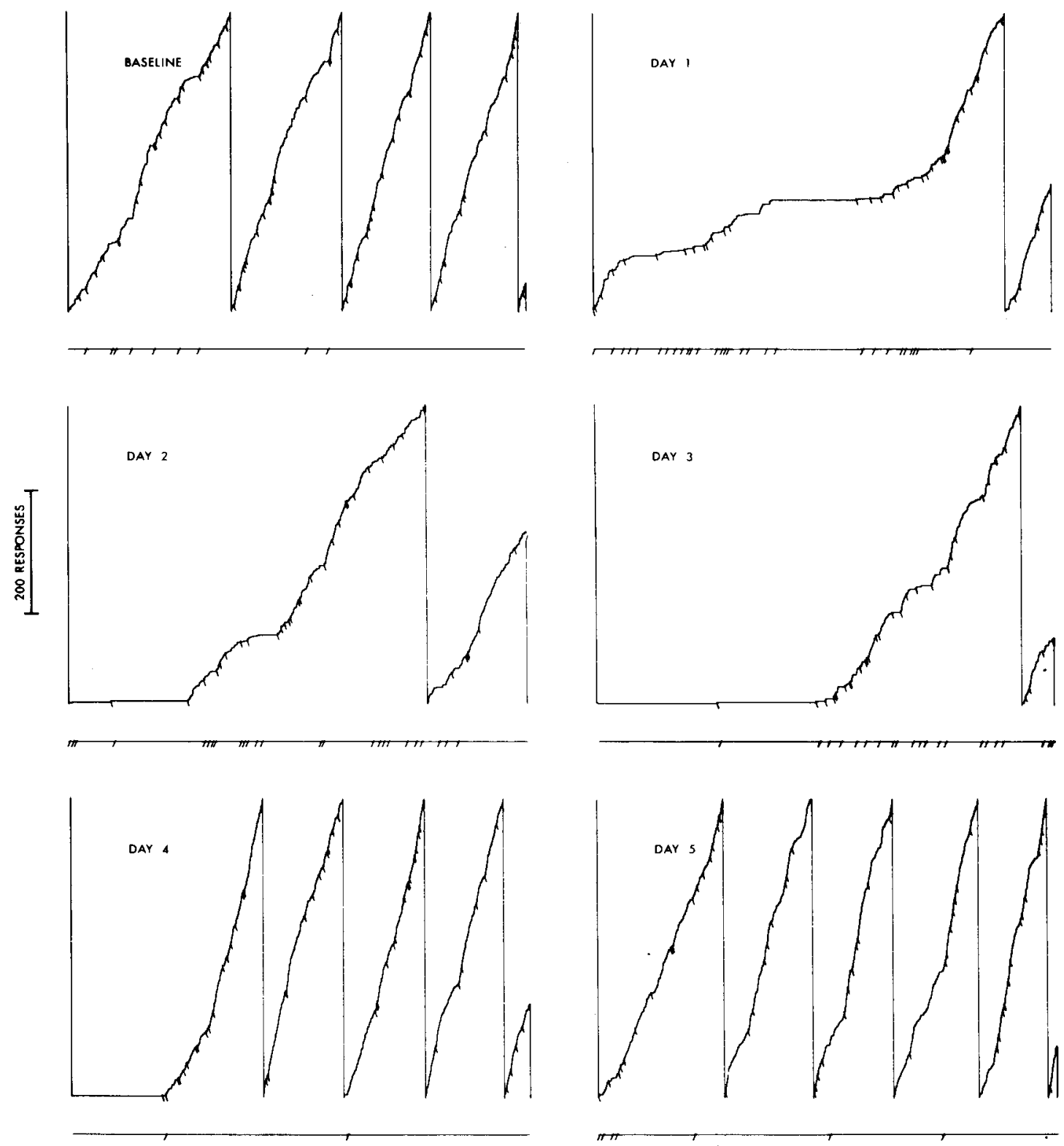

20 MINUTES

Figure 2. Cumulative records for Rat B3. The record labeled BASELINE was obtained on the last day of VI training prior to DPO exposure. The remaining records were obtained during the first 5 days of exposure to DPO. Oblique deflections of the response pen indicate reinforcement delivery; deflections of the event pen indicate pauses during baseline and punished pauses during DPO.

was not possible to obtain records for B1 during the pilot study, although response rates did reflect this same trend. Subsequent exposure to DPO, with the exception of one session for B3, did not produce this phenomenon in terms of response rate and was not evident in the cumulative records.

Changes in the number of pauses and response rate as a function of condition are also reflected in the response distributions that were obtained.
Figure 3 shows the relative frequency of responding in each IRT class for all subjects. Each distribution represents averages over the last six sessions for the specified condition. The baseline and barpressdependent punishment conditions intervening between the two NCS conditions for Rats B1 and B3 are not shown. Data from the second exposure to DPO $12 \mathrm{sec}$, as well as the immediately subsequent baseline, are not shown for G6. Note that the y-axis 

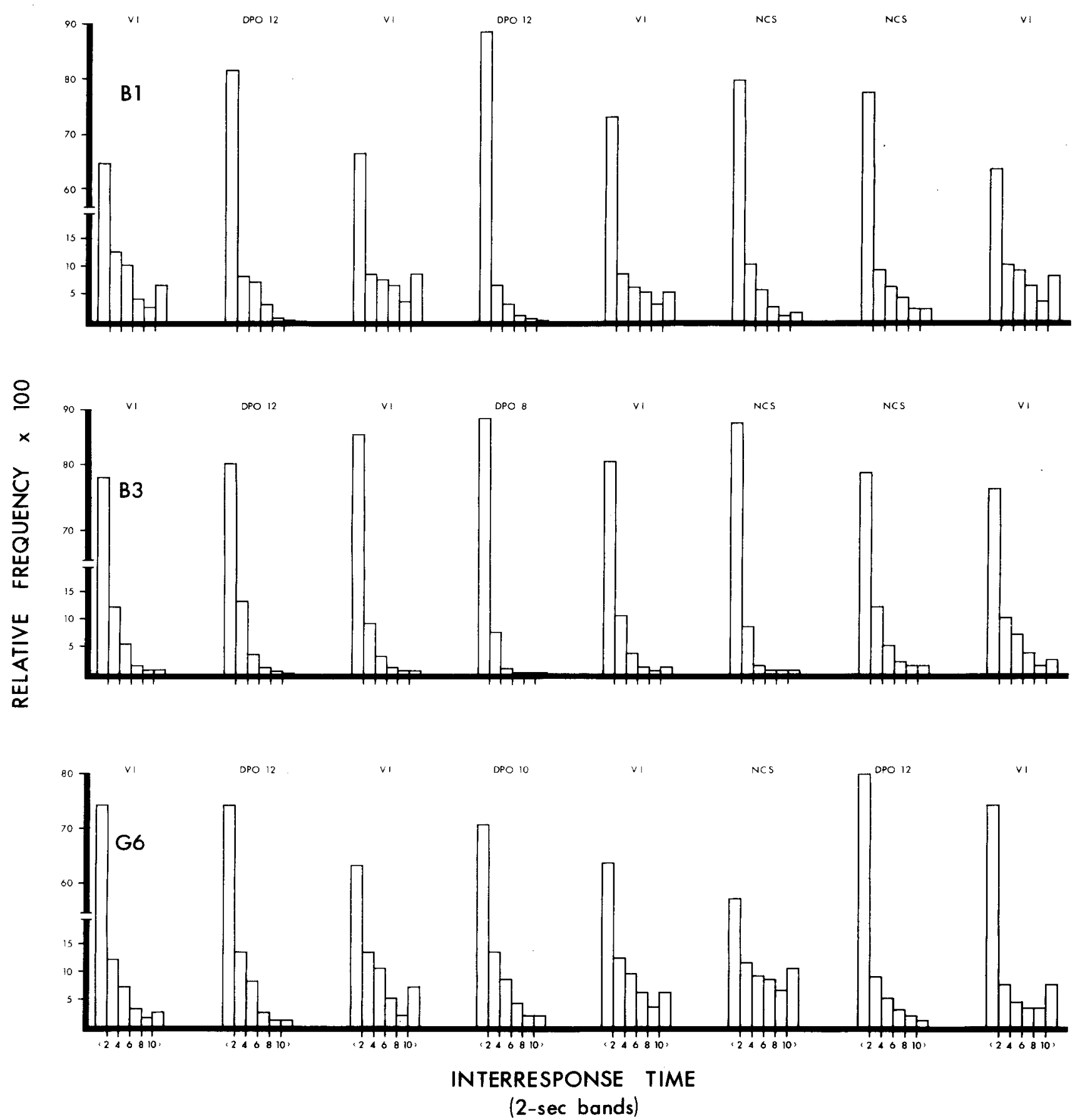

Figure 3. Distribution of responses in 2-sec classes (bands). Each distribution represents the average of the final six sessions of the condition indicated. The $y$-axis has been interrupted, but the same scale was used throughout. Some experimental conditions have been deleted from this figure.

has been interrupted, although the scale remains the same.

Responses in the 0 - to 2 -sec IRT class increased markedly during DPO, and those in the IRT class greater than or equal to the DPO value were virtually eliminated. The remaining IRT classes were not affected in a systematic fashion. Introduction of NCS following DPO training produced DPOlike distributions for Rats B1 and B3. Short IRTs became more frequent and long IRTs less frequent, although suppression of the longer IRTs was less pronounced than during either DPO condition. Ex- 
posure of Rat G6 to NCS shifted the distribution in the opposite direction. Such a shift was never obtained with B1 and B3, but exposure to NCS following barpress-dependent shock shows that the frequency of long IRTs is greater than it was during the previous NCS condition and that the frequency of short IRTs decreased.

The DPO and NCS effects were generally accompanied by small increases in reinforcement frequency (see Table 1). The increase is viewed as a consequence of the change in response rate rather than an increase in the availability of reinforcers. Furthermore, it is unlikely that such small changes in reinforcement frequency could account for the effects observed.

\section{DISCUSSION}

The present study demonstrates the sensitivity of pauses to punishment. A differential-punishmentof-other-behavior (DPO) schedule was employed whereby failure to barpress for a specified period of time since the previous barpress resulted in shock. In all cases, exposure to DPO decreased the number of specified pauses. These decreases were accompanied by increases in rate of response and a shift in the distribution to include more responses in the shorter IRT class. Exposure to responsedependent shock reduced rate of response to nearzero levels and demonstrated the punitive nature of the selected shock level. Noncontingent shock produced inconsistent effects across subjects but, in general, produced response rate increases following DPO and unsystematic effects following responsedependent shock. While it is generally found that noncontingent shock is suppressive or ineffective (e.g., Beavers \& Perkins, 1977; Schuster \& Rachlin, 1968), there are exceptions (e.g., Domjan, 1969; Herrnstein \& Sidman, 1958; Sidman, Herrnstein, \& Conrad, 1957). The current study provides an additional exception. These observations are consistent with the conclusions of Kelleher and Morse (1968) and Rachlin (1966) that a subject's history with shock is one determinant of how shock will affect behavior. Similar effects of experimental history have also been reported when positive reinforcement was used (e.g., Franks \& Lattal, 1976).

There is considerable similarity between the effects of DPO and the IRT $>t$ shock schedule used by Galbicka and Branch (1981). Both arrangements produced increased response rates and concomitant shifts in the distribution of responses. These procedures affect overall response rates inversely relative to response-dependent shock schedules, but all three procedures are similar with regard to their effect upon the targeted unit of behavior. The primary difference in these procedures is the locus of shock within the stream of behavior.
Dinsmoor (1977) has suggested that classes of behavior as diverse as responses and pauses should not be expected to condition at the same rate. Comparison of DPO and barpress-dependent shock in the current study is supportive of his remark. Although both pauses and barpresses were contiguous with shock, barpresses were more rapidly and completely suppressed. A similar prediction can be made regarding pauses and IRTs. Since IRT-dependent events directly contact barpresses, punishment of long IRTs tends to suppress all barpresses, not just those following long pauses. This should produce slower conditioning than pause-dependent shock, since barpresses are never contacted by the punisher. One indication of this, notwithstanding differences in experimental design and subject species, can be seen in the cumulative records of Rat B3 (from the current study) and Monkey M-514 (from Galbicka $\&$ Branch, 1981). For B3, local response rates similar to the prepunishment baseline were evident within $25 \mathrm{~min}$ of initial exposure; for M-514, this type of behavior was not evident for $180 \mathrm{~min}$ following initial exposure. This finding suggests pauses form part of a continuum of response specification, with narrowly defined responses, such as barpresses and keypecks, near one end and complex units, such as IRTs, near the other. As the precision of response specification lessens, the control exerted by events dependent upon these units lessens also.

An issue that is raised by the current study, although not its focal point, is whether the obtained rises in response rate and decreases in pause rate are the result of punishment or of avoidance. While the contingency was termed differential punishment of other behavior, this is a description of the contingency and not an account of its effects. This term was chosen because a response, albeit a pause, was defined and an aversive stimulus delivered dependent upon and contiguous with its emission. The specified response declined in frequency as a result of these procedures. It could be argued, however, that the decline in pauses was a secondary effect. From one avoidance perspective, the contingencies negatively reinforced barpresses, since most barpresses postponed the occurrence of shock. (Those barpresses following shock, it must be remembered, actually increased the probability of shock.) The resulting increase in response rate reduced the opportunity for long pauses.

Historically, negative reinforcement was used to describe an increase in response rate produced by the immediate termination of an aversive event (i.e., escape). Herrnstein and Hineline (1966) then extended this definition to include postponement of aversive events. Negative reinforcement has henceforth been used by many researchers as an account of unsignaled avoidance performance. The shockdensity reduction account of avoidance gained pop- 
ularity because it seemingly circumvented the hypothesizing of behaviors (internal or external) permitted with the safety signal theory and the punishment theory of avoidance. Shock-density-reduction theory has been criticized by Dinsmoor (1977) because it is difficult to envision how the absence of an event can function as a reinforcer and because the contingency is theorized to operate on complex samples of behavior. That is, patterns of responses and pauses with given properties are free of shocks, while other patterns are not. This central aspect of shock-density-reduction theory unfortunately requires analysis involving the feature it sought to eliminate: nonspecific response units (see Dinsmoor, 1977, pp. 90-91, for a detailed discussion of this problem).

The present study can be seen, in part, as an attempt to establish a functional relationship between shock and one component of these complex units, namely, pauses. It is unclear precisely how the present procedure produced the observed effects, but the following analyses are offered. Pauses are collections of nonspecified behaviors whose major defining characteristic is the absence of a measured response, that is, a barpress. Since shock was delivered with regard to time rather than any particular component of the pause unit, it seems reasonable to assume that various components of pausing were contiguous with shock. As these components declined in frequency, so did the pauses they comprised. Alternatively, shock may have served to disrupt ongoing chains of behaviors that competed with barpressing. These analyses are not incompatible with one another, but both permit tremendous post hoc flexibility in the absence of direct supporting data; this flexibility is particularly problematic with analyses that include only barpress and pause rates. Also, neither approach necessarily predicts an increase in response rate concomitant with the decrease in pause rate. For example, a subject could eliminate all pauses of $12 \mathrm{sec}$ or greater and yet emit only 10 barpress responses per minute.

A recent study by Dunham and Grantmyre (1982) seems to address both issues of response-rate increases as the result of punishment and inclusion of behaviors other than barpresses in an experimental analysis. Their study demonstrated that punishment of one member of a multiresponse repertoire produced an increase in the most probable remaining behavior. That is, punishment produced a disproportionate restructuring of the repertoire. Inspection of the current data and those presented by Galbicka and Branch (1981) reveals a similar pattern. Limiting the IRT distribution by introducing shock had little impact on those IRTs immediately preceding the limit. Instead, the IRTs that previously predominated in the distribution increased markedly as a result of experimental manipulation. Interestingly, when Bersh and Alloy (1978) shortened the response-shock interval in an avoidance paradigm, the predominant IRT class was largely unaffected. These arguments are not exhaustive, and they do not preclude a negative reinforcement analysis of the current data, but it is unclear what such an analysis would add.

The position that pauses are conditionable units of behavior is not a new one. Studies employing pause-dependent food schedules (DRO) are numerous, although not nearly so extensive as those involving discrete responses. It would seem that pauses and the behavior that comprise these units could provide valuable data for experimental analyses of behavior. For example, Bersh and Alloy (1978), in speaking of IRTs, have suggested "that the passage of time from the preceding response or some process correlated with that passage of time must be added to feedback from the current response as the critical basis for the discrimination between effective and ineffective current responses"' (p. 300). It seems reasonable to suspect that the organism's behavior could serve as the source of this information (see Latall, 1975, or Zeiler \& Solano, 1982). Alternatively, IRT-dependent schedules may function by indirectly conditioning those behaviors comprising the pause. The current study further suggests future experimentation utilizing pause-dependent and IRT-dependent event arrangements in situations such as those devised by Dunham and Grantmyre (1982). A more precise specification of the effects of contingencies on the stream of behavior might be gained if, in addition to barpresses or keypecks, other response units were quantified and included in experimental analyses.

\section{REFERENCES}

Angen, D. The dependence of interresponse times upon the relative reinforcement of different interresponse times. Journal of Experimental Psychology, 1956, 52, 145-161.

Benvers, W. O., \& Perking, C. C. Punishment of nonspecific responses: Does the negative half of the law of effect apply? Bulletin of the Psychonomic Society, 1977, 9, 14-16.

Bergh, P. J., \& Alloy, L. B. Avoidance based on shock intensity reduction with no change in shock probability. Journal of the Experimental Analysis of Behavior, 1978, 30, 293-300.

Bond, N. W., Blackman, D. E., \& Scnuton, P. Suppression of operant behavior and schedule-induced licking in rats. Journal of the Experimental Analysis of Behavior, 1973, 20, 375383.

Dinsmoor, J. A. Escape, avoidance, punishment: Where do we stand? Journal of the Experimental Analysis of Behavior, $1977,28,83-95$.

Doujan, M. P. Superstitions escape in the albino rat. Psychological Record, 1969, 19, 53-58.

Dunham, P. J., \& Grantuyre, J. Changes in a multipleresponse repertoire during response-contingent punishment and response restriction: Sequential relationships. Journal of the Experimental Analysis of Behavior, 1982, 37, 123-133. 
Ferster, C. B. Control of behavior in chimpanzees and pigeons by time out from positive reinforcement. Psychological Monographs, 1958, 72, 1-38.

Flory, R. K., \& Lickfetr, G. C. Effects of lick-contingent timeout on schedule-induced polydipsia. Journal of the Experimental Analysis of Behavior, 1974, 21, 45-55.

Franks, G. J., \& Lattal, K. A. Antecedent reinforcement schedule training and operant response reinstatement in rats. Animal Learning \& Behavior, 1976, 4, 374-378.

Galbicka, G., \& Branch, M. N. Selective punishment of interresponse times. Journal of the Experimental Analysis of Behavior, 1981, 35, 311-322.

Herrnstein, R. J., \& Hineline, P. N. Negative reinforcement as shock-frequency reduction. Journal of the Experimental Analysis of Behavior, 1966, 9, 421-430.

Herrnstein, R. J., \& Sidman, M. Avoidance conditioning as a factor in the effects of unavoidable shock on foodreinforced behavior. Journal of Comparative and Physiological Psychology, 1958, 51, 380-385.

Kelleher, R. T., \& Morse, W. H. Schedules using noxious stimuli. III. Responding maintained with response produced electric shocks. Journal of the Experimental Analysis of Behavior, 1968, 11, 819-838.

Laties, V. G., Weiss, B., Clark, R. L., \& Reynolds, M. D. Overt "mediating" behavior during temporally spaced responding. Journal of the Experimental Analysis of Behavior, 1965, $8,107-116$.

LAtTAL, K. A. Reinforcement contingencies as discriminative stimuli. Journal of the Experimental Analysis of Behavior, $1975,23,241-246$.

Lattal, K. A., \& Poling, A. D. Describing response-event relations: Babel revisited. Behavior Analyst, 1981, 4, 143-152.

RACHLIN, H. Recovery of responses during mild punishment. Journal of the Experimental Analysis of Behavior, 1966, 9, 251-263.

Rachlin, H., \& Herrnstein, R. J. Hedonism revisited: On the negative law of effect. In B. S. Campbell \& R. M. Church (Eds.), Punishment and aversive behavior. New York: Appleton, 1969.
Schuster, R., \& RAChlin, H. Indifference between punishment and free shock: Evidence for the negative law of effect. Journal of the Experimental Analysis of Behavior, 1968, 11, 777. 786.

Shimp, C. P. Probabilistically reinforced choice behavior in pigeons. Journal of the Experimental Analysis of Behavior, $1966,9,443-455$.

Shimp, C. P. The concurrent reinforcement of two interresponse times: The relative frequency of an interresponse time equals its relative harmonic length. Journal of the Experimental Analysis of Behavior, 1969, 12, 403-411.

Sidman, M., Hernnstein, R. J., \& Conrad, D. G. Maintenance of avoidance behavior by unavoidable shocks. Journal of Comparative and Physiological Psychology, 1957, 50, 553-557.

Stadpon, J. E. R. Spaced responding and choice: A preliminary analysis. Journal of the Experimental Analysis of Behavior, $1968,11,669-682$.

ZEILER, M. D. Schedules of reinforcement: The controlling variables. In W. K. Honig \& J. E. R. Staddon (Eds.), Handbook of operant behavior. New York: Prentice-Hall, 1977.

Zeiler, M. D., \& Solano N., J. M. Responses and pauses: Discrimination and a choice catastrophe. Journal of the Experimental Analysis of Behavior, 1982, 37, 223-231.

\section{NOTE}

1. While the focus of the current study was punishment of pauses, a detailed figure of pauses is not included. It was a difficult choice between the data of emphasis (pauses) and the data of convention (responses); for ease of integration with the largest body of data, convention was followed. Averaged pause data are available in Table 1, and detailed pause data will be sent with reprint requests.

(Manuscript received August 12, 1982; revision accepted for publication February 4, 1983.) 